\title{
An Electrochemical Immunosensor Based on AuNPs/ZIF- 8/helical Carbon Nanotubes Nanocomposites for the Detection of Cardiac Troponin I
}

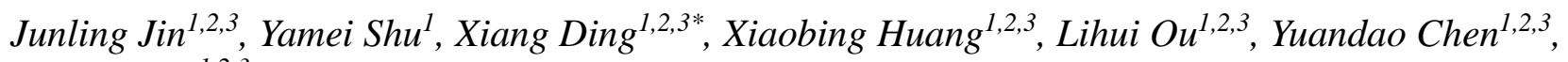 \\ Anguo Xiao ${ }^{1,2,3}$ \\ ${ }^{1}$ Hunan Province Cooperative Innovation Center for The Construction \& Development of Dongting \\ Lake Ecological Economic Zone, College of Chemistry and Material Engineering, Hunan University \\ of Arts and Science, Changde, 415000, China \\ ${ }^{2}$ Hunan Provincial Key Laboratory of Water Treatment Functional Materials \\ ${ }^{3}$ Hunan Province Engineering Research Center of Electroplating Wastewater Reuse Technology \\ *E-mail: dingxiang83@163.com
}

doi: $10.20964 / 2020.08 .78$

Received: 6 December 2019 / Accepted: 21 April 2020 / Published: 10 July 2020

\begin{abstract}
ZIF-8, one of the metal organic frameworks, has hierarchical structure and high surface area, which can be used as a carrier material for the fabrication of biosensors. However, the poor electrical conductivity hinders its applications in electrochemical biosensors. Here, using the nanocomposites of $\mathrm{Au}$ nanoparticles, metal organic frameworks and helical carbon nanotubes, we developted the immunosensor for the detection of cardiac troponin I. The thin films made of Au nanoparticles, ZIF-8 and helical carbon nanotubes were bio-interfaced with antibody for the use of immuno-electrode. The conductivity of electrode surface improved greatly by adding helical carbon nanotubes into ZIF-8. Signal measuremenst were performed by differential pulse voltammetry (DPV) technique. The proposed immunosensor was used to detect cardiac troponin I in the linear range of $0.1-40 \mathrm{ng} / \mathrm{mL}$ with a detection limit of $0.04 \mathrm{ng} / \mathrm{mL}$.
\end{abstract}

Keywords Metal organic frameworks; ZIF-8; Au nanoparticles; Helical carbon nanotube; Cardiac troponin I

\section{$\underline{\text { FULL TEXT }}$}

(C) 2020 The Authors. Published by ESG (www.electrochemsci.org). This article is an open access article distributed under the terms and conditions of the Creative Commons Attribution license (http://creativecommons.org/licenses/by/4.0/). 